\title{
Antidepressant use and mortality in Finland: a register-linkage study from a nationwide cohort
}

\author{
Jari Haukka • Martti Arffman • Timo Partonen • \\ Sinikka Sihvo • Marko Elovainio • Jari Tiihonen • \\ Jouko Lönnqvist • Ilmo Keskimäki
}

Received: 8 September 2008 / Accepted: 8 January 2009 /Published online: 5 March 2009

(C) Springer-Verlag 2009

\begin{abstract}
Background It is generally acknowledged that depressed patients need specific attention during the first weeks after initiation of antidepressant (AD) treatment because of the increased risk of suicide.

Methods The study population consisted of all individuals residing in Finland from 1999 to 2003 who had purchased a prescribed antidepressant at least once but had no preceding antidepressant prescription. Data sources were the National Prescription Register, the Causes of Death Register, Census Data of Statistics Finland, and the National Care Register. Follow-up started at the first purchase and ended at the end of 2003 or death. Data on prescriptions were used to construct contiguous treatment periods of follow-up time. Life-table analysis with Poisson regression was used to estimate risk ratios (RR) of antidepressant use with respect to all-cause mortality and to deaths from suicide.
\end{abstract}

J. Haukka $(\bowtie) \cdot$ M. Arffman • T. Partonen • S. Sihvo ·

M. Elovainio $\cdot$ J. Lönnqvist $\cdot$ I. Keskimäki

National Institute for Health and Welfare,

Helsinki, Finland

e-mail: jari.haukka@thl.fi

M. Arffman

e-mail: martti.arffman@thl.fi

J. Tiihonen

Department of Forensic Psychiatry,

University of Kuopio, Niuvanniemi Hospital,

Kuopio, Finland

J. Lönnqvist

Department of Psychiatry, University of Helsinki

and Helsinki University Central Hospital,

Helsinki, Finland
Findings Current $\mathrm{AD}$ use was associated with a lowered all-cause mortality ( $\mathrm{RR}=0.18,95 \% \mathrm{CI}=0.18-0.19)$ compared with those who filled one previous prescription only. There was no difference in suicide mortality when any current antidepressant usage was compared to the oneprescription group. Current SSRI usage was associated with lower risk of suicide compared to the one-prescription or other antidepressant groups (RR 0.47, 0.38-0.59).

Interpretation Current $\mathrm{AD}$ treatment is associated with decreased all-cause mortality rates in patients who have ever had AD treatment.

Keywords Antidepressant $\cdot$ Suicide $\cdot$ Mortality $\cdot$ SSRI

\section{Introduction}

It is acknowledged that depressed patients should be monitored intensively during the first weeks after initiation of antidepressant (AD) treatment because of temporarily increased risk of suicide [1]. However, the temporal evolution of mortality and suicide risk after discontinuation of $\mathrm{AD}$ treatment remains unknown. Based on ecological evidence, the increased use of $\mathrm{AD}$ and especially of selective serotonin re-uptake inhibitors (SSRI) is associated with decreased rate of suicides [2-6].

Still, concerns have been raised about the potential connection between antidepressant use and suicidal behavior. This has been studied using meta-analysis, case-control studies, ecological studies, and observational cohort studies. A meta-analysis based on drug company data from placebo-controlled, randomized trials indicated that increased risk of suicide and self-harm caused by SSRIs cannot be ruled out [7], but on the other hand analysis of FDA reports showed no difference in suicide risk between 
antidepressant-treated and placebo-treated depressed subjects in controlled trials [8].

A retrospective cohort study with a total of 57,361 patients and follow-up time of 120 days concluded that the observed connection between suicidal behavior and prescription of SSRIs is due to confounding by indication [9]. UK General Practice Research Database (GPRD) was used in a matched case-control study that compared risk of suicidal behavior among users of four antidepressant drugs [10]. In a nested case-control study, the adjusted odds ratio of suicide was 0.57 [ $95 \%$ confidence interval $(95 \% \mathrm{CI})$ $0.26-1.25$ ] in people prescribed SSRIs compared with those prescribed tricyclic antidepressants [11]. In a case-control study of an elderly population (66 years and older) in Canada, SSRI therapy was associated with increased risk of suicide during the month following its initiation [12]. In an ecological study of association between use of antidepressants and suicide rate in Finland, increased use of antidepressants was associated with a decline in suicide rate [13]. Similarly, the fall in suicide rates in Norway was associated with the increased sales of non-TCA antidepressants [14]. An aggregated data analysis of National Vital Statistics from the U.S. Centers for Disease Control and Prevention showed that a higher number of tricyclic antidepressants (TCA) was associated with higher suicide rates compared with SSRI use [15].

An observational, individual-level register linkage study of 15,390 patients with previous attempted suicide showed that treatment of any antidepressant was associated with increased risk of attempted suicide and, at the same time, decreased risk of completed suicide and death [16]. A recent study based on the GPRD with 219,088 patients concluded that there is excess risk of suicide associated with use of venlafaxine, which is probably due to the higher burden of suicide risk among venlafaxine users [17]. A register-based study from Denmark showed lower rate of suicides for those who continued antidepressant use compared to those who purchased once (rate ratio $0.31,95 \%$ CI $0.26-0.36$ ) [18]. On the other hand, a longitudinal register study from Finland demonstrated that lower socio-economic groups received the lowest levels of treatment despite evidence of their increased prevalence of depression and suicide [19].

The aim of this study was to investigate, in a nation-wide cohort of antidepressant users, how the risk of suicide and all-cause mortality are associated with $\mathrm{AD}$ treatment.

\section{Material and methods}

Study population

In Finland, information on causes of death is recorded by Statistics Finland. All reimbursed medication prescriptions purchased from a pharmacy are registered by the Social Insurance Institution. The linking of these registers is possible because every individual residing in Finland has a unique personal identification number.

Construction of the study population began by identifying all people who had reimbursed antidepressant prescriptions from 1999 to 2003, using the database of the National Social Insurance Institution. The study population consists of new antidepressant users and hence patients with antidepressant purchases in the preceding 5 years were excluded. Prescription data contained the personal identification number, date of purchase, anatomic therapeutic code (ATC), and amount purchased as defined daily doses (DDD) [20]. Prescription data also included information on all antipsychotic drug (ATC code N05) prescriptions, while data on prescriptions during the 5 previous years were used as background variable.

Statistics Finland provided socioeconomic background variables for the study population by record linkage using the unique personal identification numbers. The following background variables were used in analyses: sex, age at the beginning of follow-up (10-14, 15-19, 20-29, 30-39, $40-49,50-59,60-69,70-79$, and over 80 years), socioeconomic status (non-manual employee, manual employee, farmer, other entrepreneur, student, other, or unknown), marital status (married, other), employment status (employed, 0-6 months unemployed, 7-12 months unemployed, retired, or other outside of workforce), education level (basic level, secondary or higher), family net income quintile, living alone (yes, no), time since start of follow-up (first antidepressant prescription in days), and calendar year (1999-2003).

In addition, information on hospitalizations was obtained from the Care Register for Health. The following dichotomous variables for each individual were constructed, based on hospitalizations during the previous 5 years: hospital-treated attempted suicide, alcohol-dependence diagnosis (ICD-10 starting with F1), schizophrenia, schizotypal and delusional disorder (F2), mood disorder (F3), and personality disorder (F6). Causes and date of death were obtained from the Causes of Death Register of Statistics Finland. Cause of death was classified as suicide (ICD-10 X60*-X84) or all other causes. Follow-up of the individual was started at the first purchase of antidepressant medication and finished at death or the end of 2003. Thus, the longest possible length of follow-up was 5 years.

\section{Data analysis}

The duration of antidepressant treatment was calculated according to the purchased DDD [21]. Contiguous prescription periods were combined if the gap between them was shorter than 30 days. The 10 most frequently used 
Table 1 Mortality and use of antidepressants

\begin{tabular}{|c|c|c|c|c|c|c|c|c|c|}
\hline \multirow{3}{*}{$\begin{array}{l}\text { Current use of antidepressant } \\
\text { SSRI }\end{array}$} & \multirow{3}{*}{$\begin{array}{l}\text { Person years } \\
139,710\end{array}$} & \multirow{3}{*}{$\begin{array}{l}\text { All deaths }(n) \\
1,358\end{array}$} & \multirow{3}{*}{$\begin{array}{l}\text { All cause rate per } 100,000 \\
972\end{array}$} & \multicolumn{3}{|c|}{ RR unadjusted } & \multicolumn{3}{|c|}{ RR adjusted } \\
\hline & & & & \multirow{2}{*}{$\frac{\mathrm{RR}}{0.25}$} & \multicolumn{2}{|c|}{$95 \%$ CI } & \multirow{2}{*}{$\frac{\mathrm{RR}}{0.18}$} & \multicolumn{2}{|c|}{$95 \% \mathrm{CI}$} \\
\hline & & & & & 0.24 & 0.27 & & 0.17 & 0.19 \\
\hline TCA & 7,710 & 130 & 1,686 & 0.43 & 0.36 & 0.52 & 0.23 & 0.20 & 0.28 \\
\hline Other & 81,880 & 716 & 874 & 0.22 & 0.21 & 0.24 & 0.19 & 0.18 & 0.20 \\
\hline None & 340,730 & 11,704 & 3,435 & 0.88 & 0.86 & 0.91 & 0.85 & 0.82 & 0.88 \\
\hline Citalopram & 68,041 & 937 & 1,377 & 0.35 & 0.33 & 0.38 & 0.17 & 0.16 & 0.19 \\
\hline Fluoxetine & 27,502 & 187 & 680 & 0.17 & 0.15 & 0.20 & 0.20 & 0.17 & 0.23 \\
\hline Sertraline & 14,624 & 86 & 588 & 0.15 & 0.12 & 0.19 & 0.16 & 0.13 & 0.20 \\
\hline Mirtazapine & 14,270 & 211 & 1,479 & 0.38 & 0.33 & 0.44 & 0.18 & 0.15 & 0.20 \\
\hline Paroxetine & 12,839 & 61 & 475 & 0.12 & 0.09 & 0.16 & 0.22 & 0.17 & 0.29 \\
\hline Amitriptyline & 5,223 & 93 & 1,781 & 0.46 & 0.37 & 0.56 & 0.26 & 0.21 & 0.32 \\
\hline Venlafaxine & 3,592 & 28 & 780 & 0.20 & 0.14 & 0.29 & 0.23 & 0.16 & 0.33 \\
\hline Fluvoxamine & 3,176 & 14 & 441 & 0.11 & 0.07 & 0.19 & 0.16 & 0.09 & 0.27 \\
\hline Moclobemide & 2,469 & 11 & 446 & 0.11 & 0.06 & 0.21 & 0.13 & 0.07 & 0.23 \\
\hline Mianserin & 1,870 & 32 & 1,711 & 0.44 & 0.31 & 0.62 & 0.14 & 0.10 & 0.21 \\
\hline Other & 75,695 & 544 & 719 & 0.18 & 0.17 & 0.20 & 0.20 & 0.18 & 0.22 \\
\hline None & 340,730 & 11,704 & 3,435 & 0.88 & 0.86 & 0.91 & 0.85 & 0.82 & 0.88 \\
\hline All antidepressants & 229,299 & 2,204 & 961 & 0.25 & 0.24 & 0.26 & 0.18 & 0.18 & 0.19 \\
\hline One prescription & 175,708 & 6,830 & 3,887 & \multicolumn{3}{|c|}{ Reference } & \multicolumn{3}{|c|}{ Reference } \\
\hline
\end{tabular}

Rate ratios (RR with 95\% confidence interval) based on Poisson regression model with sex, age, socio-economic and medical history variables, calendar year, and follow-up time as background variables. Current antidepressant usage compared to one-prescription group

Table 2 Suicide mortality and use of antidepressants

\begin{tabular}{|c|c|c|c|c|c|c|c|c|c|}
\hline \multirow{3}{*}{$\begin{array}{l}\text { Current use of antidepressant } \\
\text { SSRI }\end{array}$} & \multirow{3}{*}{$\begin{array}{c}\text { Person years } \\
139,710\end{array}$} & \multirow{3}{*}{$\begin{array}{l}\text { Suicide } \\
123\end{array}$} & \multirow{3}{*}{$\begin{array}{l}\text { Suicide rate per } 100,000 \\
88\end{array}$} & \multicolumn{3}{|c|}{ RR unadjusted } & \multicolumn{3}{|c|}{ RR adjusted } \\
\hline & & & & \multirow{2}{*}{$\frac{\mathrm{RR}}{0.67}$} & \multicolumn{2}{|c|}{$95 \% \mathrm{CI}$} & \multirow{2}{*}{$\frac{\mathrm{RR}}{0.47}$} & \multicolumn{2}{|c|}{$95 \% \mathrm{CI}$} \\
\hline & & & & & 0.54 & 0.83 & & 0.38 & 0.59 \\
\hline TCA & 7,710 & 10 & 130 & 0.99 & 0.52 & 1.86 & 0.57 & 0.30 & 1.07 \\
\hline Other & 81,880 & 167 & 204 & 1.55 & 1.27 & 1.89 & 0.84 & 0.69 & 1.03 \\
\hline None & 340,730 & 355 & 104 & 0.79 & 0.67 & 0.94 & 0.73 & 0.61 & 0.86 \\
\hline Citalopram & 68,041 & 53 & 78 & 0.59 & 0.44 & 0.80 & 0.43 & 0.32 & 0.58 \\
\hline Fluoxetine & 27,502 & 28 & 102 & 0.77 & 0.52 & 1.15 & 0.56 & 0.38 & 0.83 \\
\hline Sertraline & 14,624 & 10 & 68 & 0.52 & 0.28 & 0.98 & 0.33 & 0.17 & 0.61 \\
\hline Mirtazapine & 14,270 & 36 & 252 & 1.92 & 1.35 & 2.73 & 0.80 & 0.56 & 1.14 \\
\hline Paroxetine & 12,839 & 13 & 101 & 0.77 & 0.44 & 1.35 & 0.52 & 0.29 & 0.90 \\
\hline Amitriptyline & 5,223 & 6 & 115 & 0.87 & 0.39 & 1.97 & 0.57 & 0.25 & 1.29 \\
\hline Venlafaxine & 3,592 & 6 & 167 & 1.27 & 0.56 & 2.86 & 0.58 & 0.26 & 1.31 \\
\hline Fluvoxamine & 3,176 & 5 & 157 & 1.20 & 0.49 & 2.90 & 0.70 & 0.29 & 1.69 \\
\hline Moclobemide & 2,469 & 4 & 162 & 1.23 & 0.46 & 3.31 & 0.82 & 0.31 & 2.22 \\
\hline Mianserin & 1,870 & 3 & 160 & 1.22 & 0.39 & 3.81 & 0.47 & 0.15 & 1.46 \\
\hline Other & 75,695 & 136 & 180 & 1.37 & 1.11 & 1.69 & 0.83 & 0.67 & 1.03 \\
\hline None & 340,730 & 355 & 104 & 0.79 & 0.67 & 0.94 & 0.72 & 0.61 & 0.86 \\
\hline All antidepressants & 229,299 & 300 & 131 & 1.00 & 0.84 & 1.18 & 0.63 & 0.53 & 0.75 \\
\hline None & 340,730 & 355 & 104 & 0.79 & 0.67 & 0.94 & 0.72 & 0.60 & 0.85 \\
\hline One prescription & 175,708 & 231 & 131 & Refer & & & Refer & & \\
\hline
\end{tabular}

Rate ratios (RR with 95\% confidence interval) based on Poisson regression model with sex, age, socio-economic and medical history variables, calendar year, and follow-up time as background variables. Current antidepressant usage compared to one-prescription group 
Table 3 Suicide mortality in youth (10-20 years of age) and use of antidepressants

\begin{tabular}{|c|c|c|c|c|c|c|c|c|c|}
\hline \multirow{3}{*}{$\begin{array}{l}\text { Current use of antidepressant } \\
\text { SSRI }\end{array}$} & \multirow{3}{*}{$\begin{array}{l}\text { Person years } \\
9,313\end{array}$} & \multirow{3}{*}{$\begin{array}{l}\text { Suicide deaths }(n) \\
7\end{array}$} & \multirow{3}{*}{$\begin{array}{l}\text { Suicide rate per } 100,000 \\
75\end{array}$} & \multicolumn{3}{|c|}{ RR unadjusted } & \multicolumn{3}{|c|}{ RR adjusted } \\
\hline & & & & \multirow{2}{*}{$\frac{\mathrm{RR}}{0.62}$} & \multicolumn{2}{|c|}{$95 \% \mathrm{CI}$} & \multirow{2}{*}{$\frac{\mathrm{RR}}{0.66}$} & \multicolumn{2}{|c|}{$95 \% \mathrm{CI}$} \\
\hline & & & & & 0.23 & 1.68 & & 0.24 & 1.82 \\
\hline Other & 3,906 & 6 & 154 & 1.28 & 0.45 & 3.59 & 0.94 & 0.33 & 2.69 \\
\hline None & 17,759 & 15 & 84 & 0.70 & 0.31 & 1.60 & 0.58 & 0.24 & 1.38 \\
\hline One prescription & 7,478 & 9 & 120 & \multicolumn{3}{|c|}{ Reference } & \multicolumn{3}{|c|}{ Reference } \\
\hline
\end{tabular}

Rate ratios (RR with 95\% confidence interval) based on Poisson regression model with sex, age, socio-economic and medical history variables, calendar year, and follow-up time as background variables. Current antidepressant usage compared to one-prescription group

substances were determined, and individuals who used only one drug category were assigned to that respective group. We used the group that had filled only one prescription ("one-prescription") of any AD purchased during follow-up period as reference group. Mixed use (i.e., several antidepressant medications) or rarely used drugs were assigned to a separate group ("other"), and "no current use of medications" composed a separate group. We also applied another grouping of drugs: "one-prescription", "SSRI", "TCA", other, or no current use of medication. All-cause mortality and mortality due to suicide during the use of antidepressants were compared with the hazard during no antidepressant use by taking into account the effect of the background variables of each individual. For each individual, the follow-up was divided into periods in which the value of time-dependent variables (i.e., antidepressant medication) was constant. Thus, the follow-up of each individual consisted of several contiguous periods, each defined with specific entry and exit times.

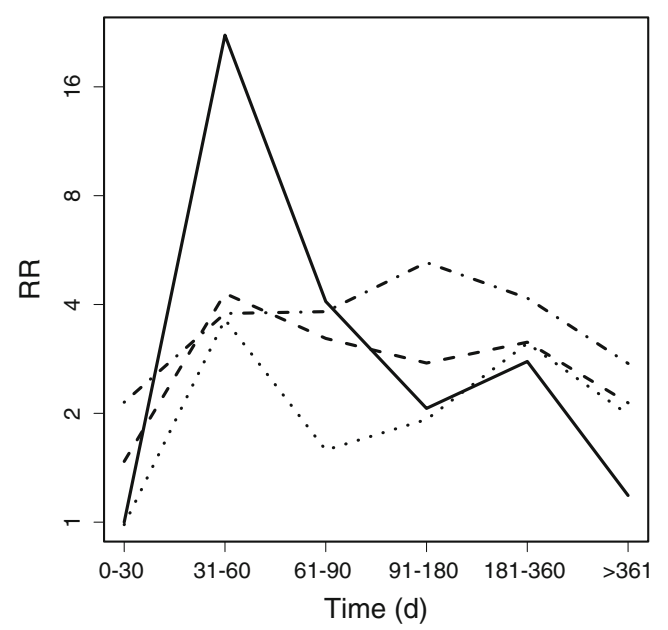

Fig. 1 Rate ratio (RR) for suicide as function of time since start of follow-up. Reference category is $0-30$ days in one-purchase group (solid line). The no-current-medication group is represented by long dashes, SSRI by short dashes, and other antidepressants by short and long dashes. The $95 \%$ confidence intervals of all groups overlap in all time periods
We constructed life tables using two time dimensions (calendar year and follow-up time), medication, and background variables. Follow-up time was divided into five intervals $(0-90,91-180,181-270,271-360$, over 360 days), and calendar year into five groups (19992003). This resulted in a table with number of events and sum of person-years in each cell. Number of events was used as the response variable and logarithm of person-years as the offset term in the generalized linear model with Poisson distribution and logarithm link function [22]. The discrete marginal variables of life tables were used as explanatory variables in the models. Results are presented as rate ratios (RR) with $95 \%$ confidence intervals.

\section{Results}

The study population consisted of 258,417 individuals who were 10 years or older and contributed 745,737 personyears. The average length of follow-up was 2.9 years. During the follow-up, 20,738 deaths were observed (including 886 suicides).

All-cause mortality during antidepressant treatment was lower than with no medication, and mortality was lower in both the group taking any antidepressant and the no antidepressant group than in the one-prescription group (Table 1). There were no clear differences among antidepressant groups or among specific substances in this regard. Adjustment with background variables increased the RR for paroxetine from 0.12 (95\% confidence interval $0.09-0.16$ ) to $0.22(0.17-0.29)$, whereas it decreased the RR of mianserin from $0.44(0.31-0.62)$ to $0.14(0.10-0.21)$.

Current use of any antidepressant was associated with a lower suicide RR of $0.63(0.53-0.75)$ compared to the oneprescription group (Table 2). Current SSRI usage was associated with lower suicide mortality compared to the oneprescription (RR 0.47, 0.38-0.59). Current SSRI usage was also associated with lower suicide mortality compared to the no-antidepressant group (Table 2). The same general difference between medication groups was apparent when specific substances were compared, however no remarkable differ- 
ence between substances could be detected. We also analyzed suicide mortality among youth from 10 to 20 years of age separately (Table 3 ). There was no significant difference between one-prescription and any of the $\mathrm{AD}$ groups (nocurrent-use, SSRI, or other AD). The usage of TCA was combined with other groups because of very low usage.

We detected significant interaction between follow-up period and medication group with respect to suicide. The risk was highest between 31 to 60 days after purchase of antidepressant for the one-purchase group. After that, risk in all groups was quite similar (Fig. 1.)

Men had a risk of all-cause mortality that was more than twice as high as women, and nonmarried people had 19\% (95\% CI 14-23\%) higher all-cause mortality risk higher risk compared to married. Being in the lowest income quintile was associated with $21 \%(14-28 \%)$ higher risk than being in the highest quintile. A history of attempted suicide, use of antipsychotics, or hospitalization was associated with higher risk with respect to both end-points.

\section{Discussion}

Current use of antidepressants was associated with the lowered risk of all-cause mortality. There were no differences between substances or groups of substances. This is in line with observations from a general population-based study [23]. The study reported that antidepressant exposure was associated with increased risk, whereas withdrawal from treatment doubled the risk. In our study, every person received at least one prescription of an antidepressant, which means that everyone with no treatment during the follow-up time had discontinued treatment.

In the follow-up of this study population, having only one prescription for an antidepressant was associated with the highest risk of suicide. As shown in Fig. 1, this is probably because the individuals with highest risk committed suicide after a short follow-up. When current use of any antidepressant was compared to the one-prescription group, no significant difference was detected, but current SSRI antidepressant use was associated with lower risk of suicide.

This study, like all observational studies, has a number of limitations. Our data included quite detailed information on socio-economic characteristics, medication, and hospitalizations. On the other hand, the lack of information about certain clinically important characteristics, such as indication of antidepressant treatment, could hinder model-based adjustments. Another limitation is that adherence rates for prescribed medications could be low [24], and thus the effect observed could be attenuated. Another shortcoming is that the duration of $\mathrm{AD}$ treatment was estimated only using purchased amount and DDD, without any information on actual prescribed daily dose. This reduces the accuracy of estimation of duration of treatment. It is also possible that accuracy differs across substances. Because our data consisted only of reimbursed medications, part of the medication periods are missing. We did not have information on hospitalization periods during follow-up. Thus, some periods without medication are due to hospitalizations. However, because the one-prescription group was used as reference category, this will not distort other comparisons. In observational studies everything can thus be confounded by indication. It is possible that close monitoring may reduce all-cause mortality.

In conclusion, our results show that the current usage of SSRI antidepressants in particular is associated with lower all-cause mortality in a population of antidepressant users. However, because of the observed increased risk of suicide at the early stages of antidepressant treatment, special attention should be paid to care immediately after starting treatment.

Acknowledgement The authors wish to thank Tiina Sevon, MSc., for the preparation of the data for research purposes.

Conflict of interest Jari Haukka has been done research collaboration with Janssen-Cilag. Jari Tiihonen has been a faculty member of the Lundbeck International Neuroscience Foundation 1997-2007, a consultant/expert member of the Advisory Board of Janssen-Cilag since 2006, a member of the Eli Lilly Advisory Board since October 2006, and a member of the Bristol Myers-Squibb Advisory Board (2002-2004). He has done research collaboration with Organon (since 2007); has received fees for giving expert opinion from Bristol MyersSquibb and GlaxoSmithKline; and has received lecture fees from Janssen-Cilag, Bristol Myers-Squibb, Eli Lilly, Pfizer, Lundbeck, GlaxoSmithKline, and Astra Zeneca. Jouko Lönnqvist has done research collaboration with Orion Corporation (2004-2007) and has received fees for giving an expert opinion from Eli Lilly (2007) and for serving as the chairman of an international meeting from JanssenCilag (2008). All other authors declare no competing interest.

\section{References}

1. Sadock BJ, Sadock VA (eds) (2000) Kaplan and Sadock's comprehensive textbook of psychiatry. Lippincott Williams and Wilkins, Philadelphia

2. Isacsson G (2000) Suicide prevention - a medical breakthrough. Acta Psychiatr Scand 102(2):113-117

3. Isacsson G, Holmgren P, Ahlner J (2005) Selective serotonin reuptake inhibitor antidepressants and the risk of suicide: a controlled forensic database study of 14,857 suicides. Acta Psychiatr Scand 111(4):286-290

4. Ludwig J, Marcotte DE (2005) Anti-depressants, suicide, and drug regulation. J Policy Anal Manage 24(2):249-272

5. Rihmer Z, Akiskal H (2006) Do antidepressants t(h)reat(en) depressives? Toward a clinically judicious formulation of the antidepressant-suicidality FDA advisory in light of declining national suicide statistics from many countries. J Affect Disord 94(1-3):3-13

6. Milane MS, Suchard MA, Wong M, Licinio J (2006) Modeling of the temporal patterns of fluoxetine prescriptions and suicide rates in the United States. PLoS Med 3(6):e190 
7. Gunnell D, Saperia J, Ashby D (2005) Selective serotonin reuptake inhibitors (SSRIs) and suicide in adults: meta-analysis of drug company data from placebo controlled, randomised controlled trials submitted to the MHRA's safety review. BMJ 330(7488):385

8. Khan A, Khan S, Kolts R, Brown WA (2003) Suicide rates in clinical trials of SSRIs, other antidepressants, and placebo: analysis of FDA reports. Am J Psychiatry 160(4):790-792

9. Didham RC, McConnell DW, Blair HJ, Reith DM (2005) Suicide and self-harm following prescription of SSRIs and other antidepressants: confounding by indication. Br J Clin Pharmacol 60 (5):519-525

10. Jick H, Kaye JA, Jick SS (2004) Antidepressants and the risk of suicidal behaviors. JAMA 292(3):338-343

11. Martinez C, Rietbrock S, Wise L, Ashby D, Chick J, Moseley J et al (2005) Antidepressant treatment and the risk of fatal and nonfatal self harm in first episode depression: nested case-control study. BMJ 330(7488):389

12. Juurlink DN, Mamdani MM, Kopp A, Redelmeier DA (2006) The risk of suicide with selective serotonin reuptake inhibitors in the elderly. Am J Psychiatry 163(5):813-821

13. Korkeila J, Salminen JK, Hiekkanen H, Salokangas RKR (2007) Use of antidepressants and suicide rate in Finland: an ecological study. J Clin Psychiatry 68(4):505-511

14. Bramness JG, Walby FA, Tverdal A (2007) The sales of antidepressants and suicide rates in Norway and its counties 1980-2004. J Affect Disord 102(1-3):1-9

15. Gibbons RD, Hur K, Bhaumik DK, Mann JJ (2005) The relationship between antidepressant medication use and rate of suicide. Arch Gen Psychiatry 62(2):165-172
16. Tiihonen J, Lönnqvist J, Wahlbeck K, Klaukka T, Tanskanen A, Jari Haukka (2006) Antidepressants and the risk of suicide, attempted suicide and overall mortality in a nation-wide cohort. Arch Gen Psychiatry 63:1358-1367

17. Rubino A, Roskell N, Tennis P, Mines D, Weich S, Andrews E (2006) Risk of suicide during treatment with venlafaxine, citalopram, fluoxetine, and dothiepin: retrospective cohort study. BMJ. doi:10.1136/bmj.39041.445104.BE

18. Søndergård L, Lopez AG, Andersen PK, Kessing LV (2007) Continued antidepressant treatment and suicide in patients with depressive disorder. Arch Suicide Res 11(2):163-175

19. Kivimäki M, Gunnell D, Lawlor DA, Smith GD, Pentti J, Virtanen M et al (2006) Social inequalities in antidepressant treatment and mortality: a longitudinal register study. Psychol Med 37:373-382

20. WHO Collaborating Centre for Drug Statistics Methodolgy (2009) ATC/DDD index. Available from: http://www.whocc.no/atcddd/. Accessed 19 January 2009

21. Benson K, Hartz AJ (2000) A comparison of observational studies and randomized, controlled trials. N Engl J Med 342(25):18781886

22. McCullagh P, Nelder J (1994) Generalized linear models, 2nd ed. Chapman and Hall, London

23. Tata LJ, West J, Smith C, Farrington P, Card T, Smeeth L et al (2005) General population based study of the impact of tricyclic and selective serotonin reuptake inhibitor antidepressants on the risk of acute myocardial infarction. Heart 91(4):465-471

24. Haynes RB, McKibbon KA, Kanani R (1996) Systematic review of randomised trials of interventions to assist patients to follow prescriptions for medications. Lancet 348(9024):383-386 